\title{
Factors affecting the use of antioxidant supplements in patients with late AMD
}

\author{
This article was published in the following Dove Press journal: \\ Clinical Ophthalmology \\ 26 June 2014 \\ Number of times this article has been viewed
}

\author{
Alice $L Y u^{\prime}$ \\ Tobias Paul' \\ Markus Schaumberger ${ }^{1}$ \\ Ulrich Welge-Lussen ${ }^{2}$ \\ 'Department of Ophthalmology, \\ Ludwig-Maximilians-University, \\ Munich, ${ }^{2}$ Department of \\ Ophthalmology, Friedrich-Alexander- \\ University, Erlangen, Germany
}

Background: The purpose of this study was to assess the use of oral antioxidant supplements in patients with late age-related macular degeneration (AMD) and to identify influencing factors that may affect the use of such supplements.

Methods: The study included 47 patients with late AMD. Using a questionnaire, the patients were asked for their demographic, ophthalmologic, and systemic data, their source of recommendation of antioxidant use for AMD, and/or their reasons for nonuse. The demographic, ophthalmologic, and systemic information was correlated with use or nonuse of oral antioxidant supplements for AMD.

Results: Sixty-eight percent (32/47) of patients took antioxidant supplements for AMD and 32\% (15/47) of patients did not. There were no statistically significant differences in demographic, ophthalmologic, and systemic parameters between patients with late AMD who used supplements and those who did not. Two thirds of patients with late $\operatorname{AMD}(66 \%, 31 / 47)$ reported being recommended oral antioxidant supplements for AMD by their ophthalmologist. Patients who did not use antioxidant supplements either did not obtain any recommendation or did not believe in their benefits.

Conclusion: This study shows that most patients with late AMD use antioxidant supplements despite the recommendation to do so being missing in the Age-Related Eye Disease Study. Our study emphasizes the importance of seeking further therapeutic options for patients with late AMD.

Keywords: age-related macular degeneration, antioxidants, micronutrients, Age-Related Eye Disease Study

\section{Introduction}

Age-related macular degeneration (AMD) is a multifactorial disease of the elderly, which eventually leads to severe central vision loss in the final stages. ${ }^{1-3}$ Until now, the pathogenesis of AMD has been poorly understood, but both genetic and environmental factors are involved in the development and progression of AMD. ${ }^{4}$ While genetic factors cannot be modified, various studies indicate that environmental factors, such as oxidative stress, may decrease with use of oral antioxidants. ${ }^{5}$ In 2001, the AgeRelated Eye Disease Study (AREDS) was the first large, multicenter, randomized, placebo-controlled study to demonstrate a protective effect of antioxidants and zinc in patients with an increased risk of developing advanced AMD. ${ }^{6}$ AREDS demonstrated that patients with category 3 or 4 AMD could reduce their risk of progression to advanced AMD by regular use of AREDS supplementation, consisting of daily oral tablets containing $500 \mathrm{mg}$ vitamin C, $400 \mathrm{IU}$ vitamin E, $80 \mathrm{mg}$ zinc, $2 \mathrm{mg}$ copper, and $15 \mathrm{mg}$ beta-carotene for nonsmokers. However, patients with early AMD (AREDS category 1 or 2) or late (bilateral advanced) AMD did not benefit from these AREDS supplements. Nonetheless, a great number of patients, in particular those with late AMD, are currently taking the AREDS supplements despite the missing evidence of
Ludwig-Maximilians-University,

Department of Ophthalmology,

Mathildenstrasse 8, 80336 Munich,

Germany

Tel +49895I6038II

Fax +498951605160

Email alice.yu@med.uni-muenchen.de 
benefit. ${ }^{7}$ Until now, little has been published on the actual use of AREDS supplementation in patients with late AMD.

The purpose of this study was to assess the use of oral antioxidant supplements by patients with late AMD and to identify factors that may affect their use or nonuse.

\section{Materials and methods}

This was a questionnaire-based study on the use of oral antioxidant supplements in patients with late (bilateral advanced) AMD. Informed written consent was given by all patients before inclusion of their data into this study. This study was performed in accordance with the ethical standards laid down in the 1964 Declaration of Helsinki and was approved by the local ethics committee.

Patients with AMD were graded into category 1 to 4 or late AMD according to the AREDS classification ${ }^{6}$ during their visits to the University Eye Hospital, LudwigMaximilians-University, Munich, Germany. Category 1 was essentially free of AMD with a total drusen area less than five small drusen $(<63 \mu \mathrm{m})$ and visual acuity of 20/32 or better in both eyes. Category 2 was defined as early or borderline AMD (multiple small drusen, single or nonextensive intermediate drusen [64-124 $\mu \mathrm{m}$ ], pigment abnormalities, or any combination of these) in one or both eyes and a visual acuity of 20/32 or better in both eyes. Category 3 included intermediate AMD (with at least one large drusen [125 $\mu \mathrm{m}$ ], extensive intermediate drusen, or geographic atrophy that did not involve the center of the macula, or any combination of these) in one or both eyes, a visual acuity of 20/32 or better in at least one eye, and absence of advanced AMD in both eyes. Category 4 was defined as no advanced AMD and visual acuity of 20/32 or better in one eye, and advanced AMD (geographic atrophy involving the center of the macula or features of choroidal neovascularization) or visual acuity less than 20/32 and AMD abnormalities sufficient to explain reduced visual acuity in the fellow eye. Fundus photography or optic coherence tomography was performed to document the status of the macula. Only patients with late (bilateral advanced) AMD were included in the study. Each patient underwent a standardized clinical eye examination consisting of best-corrected visual acuity using standardized acuity charts, intraocular pressure measurements by Goldmann applanation tonometry, slit-lamp biomicroscopy, and dilated fundus examination by indirect ophthalmoscopy.

A questionnaire concerning oral antioxidant supplement use for AMD was distributed among patients with late AMD who agreed to participate in this study. Each item in the questionnaire was read by one of the study investigators so that even patients with severe vision loss or reading ability could be included into the study. Exclusion criteria included refusal to participate, a history of dementia, or language barriers. The questionnaire collected data about patient age, gender, weight, height, living situation, history of smoking, schooling, professional qualifications, family history of blindness, number of antivascular endothelial growth factor therapies, frequency of eye doctor visits, knowledge about AMD, use/ dosage/duration of oral antioxidant supplements for AMD, belief in benefit of antioxidant supplements for AMD, source of recommendation for antioxidant supplement use, reasons for nonuse of antioxidant supplements, general vitamin use, use of other oral medication, physical health limitations, awareness of healthy eating, and recreational activities, such as reading, sewing, handcrafts, or drawing.

Statistical analyses were performed using Statistical Package for the Social Sciences version 19.0 software (SPSS Inc, Chicago, IL, USA). Mean values and standard deviations were calculated by descriptive statistics. To compare values in the different groups, Mann-Whitney $U$ tests were conducted. Fisher's exact tests were used to analyze contingency tables. $P$-values $<0.05$ were regarded as statistically significant.

\section{Results}

\section{Demographics and basic characteristics}

Of the 47 patients with late (bilateral advanced) AMD, $32(68.1 \%)$ reported taking antioxidant supplementation for AMD (users), while 15 (31.9\%) did not take any oral antioxidants (nonusers). The patient age was $78.0 \pm 7.6$ years and mean body mass index was $25.9 \pm 4.2$. The study included 25.5\% (12/47) males and 74.5\% (35/47) females. Most patients were nonsmokers at the time of the study $(91.5 \%$; 43/47). About two thirds of patients lived with a partner $(66.0 \% ; 31 / 47)$, while one third lived alone $(31.9 \% ; 15 / 47)$. Approximately half of the patients $(46.8 \% ; 22 / 47)$ had a higher school degree, while the other half had a lower/no school degree $(53.2 \% ; 25 / 47) ; 57.5 \%(27 / 47)$ had a professional education, $17.0 \%(8 / 47)$ had a university degree, and $25.5 \%$ (12/47) had no professional education. There were no significant differences in any demographic parameters between users and nonusers of antioxidant supplements (Table 1).

\section{Ophthalmologic data}

Among users of antioxidant supplements, the mean number of anti-vascular endothelial growth factor injections was higher (11.0 \pm 8.5$)$ than among nonusers (6.7 \pm 5.2$)$, although 
Table I Demographic data

\begin{tabular}{|c|c|c|c|c|}
\hline Parameters & $\begin{array}{l}\text { Total } \\
(n=47)\end{array}$ & $\begin{array}{l}\text { Users } \\
(n=32)\end{array}$ & $\begin{array}{l}\text { Nonusers } \\
(n=15)\end{array}$ & $P$-value \\
\hline Age (mean $\pm S D$, years) & $78.0 \pm 7.6$ & $77.4 \pm 7.1$ & $79.3 \pm 8.6$ & 0.267 \\
\hline $\mathrm{BMI}\left(\right.$ mean $\left.\pm \mathrm{SD}, \mathrm{kg} / \mathrm{m}^{2}\right)$ & $25.9 \pm 4.2$ & $25.1 \pm 3.2$ & $27.6 \pm 5.5$ & 0.186 \\
\hline Male & $12(25.5 \%)$ & 7 (21.9\%) & $5(33.3 \%)$ & $0.48 I$ \\
\hline Female & 35 (74.5\%) & $25(78.1 \%)$ & $10(66.7 \%)$ & \\
\hline Smoker & $4(8.5 \%)$ & $3(9.4 \%)$ & I (6.7\%) & 0.707 \\
\hline Ex-smoker & $14(29.8 \%)$ & $8(25.0 \%)$ & $6(40.0 \%)$ & \\
\hline Nonsmoker & $29(61.7 \%)$ & $21(65.6 \%)$ & $8(53.3 \%)$ & \\
\hline Living alone & 15 (31.9\%) & $9(28.1 \%)$ & $6(40.0 \%)$ & 0.669 \\
\hline Living with partner & $31(66.0 \%)$ & $22(68.8 \%)$ & $9(60.0 \%)$ & \\
\hline Living with assisted care & I (2.I\%) & I (3.1\%) & - & \\
\hline Higher school degree & $22(46.8 \%)$ & $16(50.0 \%)$ & $6(40.0 \%)$ & 0.550 \\
\hline Lower/no school degree & $25(53.2 \%)$ & $16(50.0 \%)$ & $9(60.0 \%)$ & \\
\hline University degree & $8(17.0 \%)$ & 7 (21.9\%) & I (6.7\%) & 0.395 \\
\hline Professional education & $27(57.5 \%)$ & $18(56.2 \%)$ & $9(60.0 \%)$ & \\
\hline No professional education & $12(25.5 \%)$ & 7 (21.9\%) & 5 (33.3\%) & \\
\hline
\end{tabular}

Abbreviations: BMI, body mass index; SD, standard deviation.

the difference was not statistically significant $(P=0.134)$. For all other ophthalmologic parameters, including family history of blindness, number of eye doctor visits, and knowledge about AMD, no significant differences were found between users and nonusers (Table 2).

\section{Systemic data}

There were no significant differences in general vitamin use, numbers of medications, physical restrictions, healthy dietary habits, or recreational activities requiring good vision between users and nonusers. Among users, a trend towards healthy dietary habits was detected $(P=0.072$; Table 3$)$.

\section{Source of recommendation for use of oral antioxidant supplements}

Interestingly, most patients with late AMD in our study reported that they were recommended to take oral antioxidant supplements for AMD by their referring ophthalmologist $(66.0 \% ; 31 / 47)$. Only $21.3 \%(10 / 47)$ of patients reported that they did not receive any recommendation for antioxidant supplements for AMD. A minority had been informed about oral antioxidant supplement use for AMD by pharmacists $(2.1 \% ; 1 / 47)$, newspapers/magazine $(2.1 \% ; 1 / 47)$, the Internet $(4.3 \% ; 2 / 47)$, or friends $(4.3 \% ; 2 / 47$, Table 4$)$.

\section{Users of oral antioxidant supplements for AMD}

Thirty-two patients reported using oral antioxidant supplements for AMD (users), although three could not name the supplements they were taking. Among the remaining 29 users, who knew the name and dosage of their supplements, $21(72.4 \%)$ took the dose of antioxidants recommended in the package insert for the supplement. Eight patients $(27.6 \%)$ did not take the recommended dosage of supplements (Table 5).

The mean duration of supplementation in the patients using antioxidants for AMD was 41.2 \pm 39.3 (range 1-132) months. Interestingly, only half of the patients taking oral

Table 2 Ophthalmologic data

\begin{tabular}{|c|c|c|c|c|}
\hline Parameters & $\begin{array}{l}\text { Total } \\
(n=47)\end{array}$ & $\begin{array}{l}\text { Users } \\
(n=32)\end{array}$ & $\begin{array}{l}\text { Nonusers } \\
(n=15)\end{array}$ & P-value \\
\hline Family history of blindness & $7(14.9 \%)$ & $6(18.8 \%)$ & I (6.7\%) & 0.404 \\
\hline No family history of blindness & $40(85.1 \%)$ & $26(81.2 \%)$ & 14 (93.3\%) & \\
\hline Anti-VEGF treatments (mean $\pm \mathrm{SD}$ ) & $9.6 \pm 7.8$ & $11.0 \pm 8.5$ & $6.7 \pm 5.2$ & 0.134 \\
\hline Eye doctors' visits once or less per year & $6(12.8 \%)$ & $5(15.6 \%)$ & I (6.6\%) & 0.365 \\
\hline Eye doctors' visits 2-3 times per year & $15(31.9 \%)$ & $8(25.0 \%)$ & $7(46.7 \%)$ & \\
\hline Eye doctors' visits $\geq 4$ times per year & $26(55.3 \%)$ & $19(59.4 \%)$ & $7(46.7 \%)$ & \\
\hline Good/average knowledge of AMD & $24(51.1 \%)$ & $17(53.1 \%)$ & $7(46.7 \%)$ & 0.760 \\
\hline Little/no knowledge of AMD & $23(48.9 \%)$ & 15 (46.9\%) & $8(53.3 \%)$ & \\
\hline
\end{tabular}

Abbreviations: AMD, age-related macular degeneration; SD, standard deviation; VEGF, vascular endothelial growth factor. 
Table 3 Systemic data

\begin{tabular}{|c|c|c|c|c|}
\hline Parameters & $\begin{array}{l}\text { Total } \\
(n=47)\end{array}$ & $\begin{array}{l}\text { Users } \\
(n=32)\end{array}$ & $\begin{array}{l}\text { Nonusers } \\
(n=15)\end{array}$ & P-value \\
\hline General vitamin use & $10(21.3 \%)$ & $6(18.8 \%)$ & $4(26.7 \%)$ & 0.704 \\
\hline Medication $\leq 3$ tablets & $24(51.1 \%)$ & $14(43.8 \%)$ & $10(66.7 \%)$ & 0.411 \\
\hline Medication 4-6 tablets & 14 (29.8\%) & II (34.3\%) & $3(20.0 \%)$ & \\
\hline Medication $>6$ tablets & $9(19.1 \%)$ & $7(21.9 \%)$ & $2(13.3 \%)$ & \\
\hline No/little physical restrictions & $29(61.7 \%)$ & $20(62.5 \%)$ & $9(60.0 \%)$ & 1.000 \\
\hline Large physical restrictions & $18(38.3 \%)$ & $12(25.5 \%)$ & $6(40.0 \%)$ & \\
\hline Healthy diet & $4 \mathrm{I}(87.2 \%)$ & $30(93.8 \%)$ & II (73.3\%) & 0.072 \\
\hline No healthy diet & $6(12.8 \%)$ & $2(6.2 \%)$ & $4(26.7 \%)$ & \\
\hline $\begin{array}{l}\text { Recreational activities requiring } \\
\text { good vision (eg, reading) }\end{array}$ & $29(61.7 \%)$ & $22(68.8 \%)$ & $7(46.6 \%)$ & 0.170 \\
\hline
\end{tabular}

antioxidant supplements for AMD reported believing in the benefits of these supplements $(50.0 \% ; 16 / 32)$, whereas the other half did not believe in their benefits but were using them $(50.0 \% ; 16 / 32$, Table 6$)$.

\section{Reasons for nonuse of oral antioxidant supplements}

In the final part of our questionnaire, we asked patients who did not use any antioxidant supplements (nonusers) to indicate the reasons for their nonuse. Multiple answers were allowed. The most common reason nonuse was lack of belief in the benefit of oral antioxidant supplements. There were ten patients who did not receive any recommendation to take antioxidant supplements for AMD. Apart from that, four patients did not see any necessity for antioxidant supplements because of an already healthy diet. Financial cost, side effects experienced, fear of side effects, forgetfulness, and already taking too many medications did not play any role in the decision to take or not take oral antioxidant supplements in patients with late AMD (Table 7).

\section{Discussion}

AREDS ${ }^{6}$ showed that intake of a particular antioxidant combination and zinc supplements reduced the risk of progression to advanced AMD (defined as choroidal neovascularization

Table 4 Source of recommendation for use of antioxidant supplements

\begin{tabular}{ll}
\hline Source & Total $(\mathbf{n}=\mathbf{4 7})$ \\
\hline Ophthalmologist & $3 \mathrm{I}(66.0 \%)$ \\
Pharmacist & $\mathrm{I}(2.1 \%)$ \\
Newspaper/magazine & $\mathrm{I}(2.1 \%)$ \\
Internet & $2(4.3 \%)$ \\
Friend & $2(4.3 \%)$ \\
Relative & - \\
No recommendation & $10(21.3 \%)$ \\
\hline
\end{tabular}

or geographic atrophy involving the central macula) and to severe vision loss (of at least 15 letters). This benefit was seen in patients with AMD of AREDS category 3 or 4 . Since the AREDS supplements are currently the only treatment option for patients with dry AMD, patients with AMD of other than category 3 and 4 may also be inclined to take AREDS supplements. In this study, we evaluated use of oral antioxidant supplements in patients with late (bilateral advanced) AMD. We detected that almost $70 \%$ of our patients with late AMD were taking oral antioxidant supplements for AMD, although no benefit was anticipated by AREDS. Interestingly, a similar rate of use was also found in patients with AMD category 3 or 4 who were shown to benefit from the AREDS formula. ${ }^{8,9}$ AREDS also reported a $71 \%$ rate of adherence to their study tablets. ${ }^{6}$

Few studies have analyzed use of antioxidant supplements in patients with AMD other than category 3 or $4 .{ }^{9} \mathrm{In}$ Hochstetler et $\mathrm{al}^{9}$ nearly $50 \%(6 / 13)$ of patients with late AMD in both eyes and about 36\% (4/11) of patients with early AMD category 1 or 2 took antioxidant supplements for AMD. Therefore, in their study, about $40 \%(10 / 24)$ of patients who were noneligible for AREDS supplementation took antioxidant supplements. During our study, we only identified two patients with early AMD of category 1 or 2, which may be explained by the fact that our hospital is a tertiary referral center. Thus, no conclusion on supplement use by patients with early AMD could be made.

Another purpose of this study was to identify factors that may influence the use or nonuse of oral antioxidant supplements for AMD. We did not find any significant differences in demographic, ophthalmologic, or systemic parameters between patients with bilateral late AMD taking antioxidant supplements and those not taking supplements. The only trend that could be detected was the observation that patients using oral antioxidant supplements reported eating a healthy 
Table 5 Patients taking antioxidant supplements who could specify their supplements $(n=29)$

\begin{tabular}{|c|c|c|c|}
\hline Supplements & $\begin{array}{l}\text { Recommended dosage } \\
\text { according to package } \\
\text { leaflet }\end{array}$ & $\begin{array}{l}\text { Patients taking } \\
\text { recommended dosage } \\
(n=21)\end{array}$ & $\begin{array}{l}\text { Patients not taking } \\
\text { recommended dosage } \\
(\mathrm{n}=8)\end{array}$ \\
\hline Lutax ${ }^{\circledR}$ AMD & $3 \times$ per day & 0 & 3 \\
\hline Nutrof ${ }^{\circledR}$ Omega & IXper day & I & 0 \\
\hline Ocuvite $^{\circledast}$ Lutein AMD & $2 \times$ per day & 4 & 5 \\
\hline Orthomol AMD Extra ${ }^{\circledR}$ & IXper day & 5 & 0 \\
\hline Orthomol Vision ${ }^{\circledR}$ AMD & IXper day & 2 & 0 \\
\hline Vitalux ${ }^{\circledast}$ Plus & Ixper day & 9 & 0 \\
\hline
\end{tabular}

Notes: Lutax ${ }^{\circledR}$ AMD (Santen, Tampere, Finnland); Nutrof ${ }^{\circledR}$ Omega (Thea Pharma, Berlin, Germany); Ocuvite ${ }^{\circledR}$ Lutein AMD (Bausch\&Lomb, Berlin, Germany); Orthomol AMD Extra ${ }^{\circledR}$ (Orthomol, Langenfeld, Germany); Orthomol Vision ${ }^{\circledR}$ AMD (Orthomol, Langenfeld, Germany); and Vitalux ${ }^{\circledR}$ Plus (Alcon Pharma, Freiburg, Germany).

Abbreviation: AMD, age-related macular degeneration.

diet more often than patients not using supplements. Unlike the AREDS, ${ }^{6}$ in which $57 \%$ of participants were already on vitamin supplementation, most patients in our study did not take any vitamin compounds for their general health at all. According to our study results, general use of vitamins did not predict intake of antioxidant supplements for AMD. Therefore, it may be assumed that patients with AMD deliberately chose to take antioxidant supplements in order to prevent deterioration of vision.

Despite the lack of evidence for a benefit of antioxidant supplementation in patients with bilateral advanced AMD, most patients stated that it was their ophthalmologist who recommended oral antioxidant supplements for AMD. Interestingly, most patients with late AMD reported that they did know about the lack of evidence for a benefit of such supplements. Nonetheless, they still believed that their supplement use would improve their vision. As expected, the main reasons for patients with late AMD not using antioxidant supplements was that they had not been recommended and/or that patients did not believe in their benefits. However, in contrast with previous reports, ${ }^{10,11}$ we did not find that financial cost was a decisive factor for supplement use or nonuse. We supposed that patients with late AMD and severe vision loss might seek optimal therapy independent of financial interests or evidence-based recommendations.

Our results should be interpreted in light of several study limitations. First, this study included a relatively small number of patients with advanced AMD in both eyes, so

Table 6 Patients with antioxidant supplement use $(n=32)$

\begin{tabular}{ll}
\hline Parameters & Users $(\mathbf{n}=\mathbf{2})$ \\
\hline Duration of intake (mean \pm SD, months) & $41.2 \pm 39.3$ \\
Belief in AREDS benefit & $16(50.0 \%)$ \\
No belief in AREDS benefit & $16(50.0 \%)$ \\
\hline
\end{tabular}

Abbreviations: SD, standard deviation; AREDS, Age-Related Eye Disease Study. could only reflect a trend of behavior. Second, it was based on a self-report survey of AMD patients, which could overestimate supplement use. Patients are more likely to give socially acceptable answers in self-report questionnaires. ${ }^{12} \mathrm{We}$ tried to overcome this problem by asking the exact name and dosing regimen of the supplement the patients used. This question required the patients to at least know about the antioxidant supplement they were using. Third, the questionnaire was only administered to patients in our hospital, which is a tertiary referral center and may not represent the general population of patients with AMD. Finally, a more extensive and indepth survey on provision of information, understanding of the disease, and behavioral issues relating to taking of supplements would have probably been helpful in interpreting our results.

In conclusion, this study shows that most patients with late AMD actually use oral antioxidant supplements for AMD despite the lack of evidence of benefit. We would assume a strong desire on the part of patients with late AMD to obtain therapeutic assistance. Our study also emphasizes the importance of further studies to achieve more evidence on potential therapeutic approaches for patients with bilateral advanced AMD.

Table 7 Reasons for nonuse of antioxidant supplements (multiple answers possible)

\begin{tabular}{ll}
\hline Parameters & Nonusers $(\mathbf{n}=\mathbf{1 5})$ \\
\hline No recommendation & 10 \\
No belief in supplements & 15 \\
Already healthy diet & 4 \\
Cost & $\mathrm{I}$ \\
Experienced side effects & $\mathrm{I}$ \\
Fear of side effects & $\mathrm{I}$ \\
Forgetfulness & - \\
Too many medications & - \\
Advised against supplements & 3 \\
\hline
\end{tabular}




\section{Disclosure}

The authors have no financial or proprietary interest in any material or method used in this study. The data reported here comprise part of the medical thesis of Tobias Paul at the medical school of the Ludwig-Maximilians-University, Munich, Germany.

\section{References}

1. Hawkins BS, Bird A, Klein R, West SK. Epidemiology of age-related macular degeneration. Mol Vis. 1999;5:26.

2. Vingerling JR, Klaver CC, Hofman A, de Jong PT. Epidemiology of age-related maculopathy. Epidemiol Rev. 1995;17:347-360.

3. Klaver CC, Wolfs RC, Vingerling JR, Hofman A, de Jong PT. Agespecific prevalence and causes of blindness and visual impairment in an older population: the Rotterdam Study. Arch Ophthalmol. 1998;116: 653-658.

4. Chen Y, Bedell M, Zhang K. Age-related macular degeneration: genetic and environmental factors of disease. Mol Interv. 2010;10: 271-281.

5. Aslam T, Delcourt C, Silva R, et al. Micronutrients in age-related macular degeneration. Ophthalmologica. 2013;229:75-79.
6. Age-Related Eye Disease Study Research Group. A randomized, placebo-controlled, clinical trial of high-dose supplementation with vitamins $\mathrm{C}$ and $\mathrm{E}$, beta carotene, and zinc for advanced age-related macular degeneration and vision loss: AREDS report no. 8. Arch Ophthalmol. 2001;119: 1417-1436.

7. McBee WL, Lindblad AS, Ferris FL 3rd. Who should receive oral supplement treatment for age-related macular degeneration? Curr Opin Ophthalmol. 2003;14:159-162.

8. Charkoudian LD, Gower EW, Solomon SD, Schachat AP, Bressler NM, Bressler SB. Vitamin usage patterns in the prevention of advanced agerelated macular degeneration. Ophthalmology. 2008;115:1032-1038.e4.

9. Hochstetler BS, Scott IU, Kunselman AR, Thompson K, Zerfoss E. Adherence to recommendations of the age-related eye disease study in patients with age-related macular degeneration. Retina. 2010;30: $1166-1170$

10. Ng WT, Goggin M. Awareness of and compliance with recommended dietary supplement among age-related macular degeneration patients. Clin Exp Ophthalmol. 2006;34:9-14.

11. Fahed DC, Ghazi NG, Jabbour NM, Fahed CD, Fahed JC, Salti HI. Impact of AREDS in a developing country 5 years after publication of the study. Eur J Ophthalmol. 2011;21:67-72.

12. Daniels T, Goodacre L, Sutton C, Pollard K, Conway S, Peckham D. Accurate assessment of adherence: self-report and clinician report vs electronic monitoring of nebulizers. Chest. 2011;140:425-432.
Clinical Ophthalmology

\section{Publish your work in this journal}

Clinical Ophthalmology is an international, peer-reviewed journal covering all subspecialties within ophthalmology. Key topics include: Optometry; Visual science; Pharmacology and drug therapy in eye diseases; Basic Sciences; Primary and Secondary eye care; Patient Safety and Quality of Care Improvements. This journal is indexed on

\section{Dovepress}

PubMed Central and CAS, and is the official journal of The Society of Clinical Ophthalmology (SCO). The manuscript management system is completely online and includes a very quick and fair peer-review system, which is all easy to use. Visit http://www.dovepress.com/ testimonials.php to read real quotes from published authors. 